\section{There's More Than One Way to Skin a Book: Experimental Interfaces for Reading Illustrated Books}

VOLUME 3 / ISSUE 4 / 2012

\author{
Jon Bath \& Craig Harkema \\ University of Saskatchewan
}

\begin{abstract}
Different readers approach a text in different ways and for different reasons, so designers of interfaces for electronic reading and scholarship must strive for flexibility. Eric Gill's illustrations for the Golden Cockerel Press invite exploration into the social function of erotic texts, public versus private reading, fine book-making practices, and more, and we hope to provide the tools to allow scholars to engage with these texts in their multiplicity. There may also be readers who just want to read the texts and look at the pictures, and we need to make sure we do not ignore their needs. Most importantly, there are, or will be, readers who want to interact with the texts in ways that we cannot imagine, and we need to do all we can to make this experimentation possible.
\end{abstract}

\section{Keywords}

Interface design; Image collections; Book design; Book illustration; Reading; Data visualization

\section{CCSP Press}

Scholarly and Research Communication

Volume 3, Issue 4, Article ID 040142, 8 pages

Journal URL: www.src-online.ca

Received March 22, 2012, Accepted March 22, 2012, Published April 10, 2013

Bath, Jon, \& Harkema, Craig. (2012). There's More Than One Way to Skin a Book: Experimental Interfaces for Reading Illustrated Books. Scholarly and Research Communication, 3(4): 040142, 8 pp.

(C) 2012 Jon Bath \& Craig Harkema. This Open Access article is distributed under the terms of the Creative Commons Attribution Non-Commercial License (http://creativecommons.org/licenses/by-nc-nd/2.5/ca), which permits unrestricted non-commercial use, distribution, and reproduction in any medium, provided the original work is properly cited.
Jon Bath is Director of the Fine Arts and Humanities Digital Research Centre at the University of Saskatchewan. He studies and teaches the past, present, and future of books and other technologies of reading. Email: jon.bath@usask.ca .

Craig Harkema is the Digital Projects Librarian at the University of Saskatchewan. His research interests include metadata for digital initiatives, humanities computing, and information architecture. Email: craig.harkema@usask. 


\section{Scholarly and Research} Communication

VOLUME 3 / ISSUE $4 / 2012$
In 1924 Robert and Moira Gibbings purchased the Golden Cockerel Press and it quickly rose to prominence as the primary vehicle for wood-block engravers practicing in England. Robert Gibbings was a founding member of the Society of Wood Engravers in Britain, and under the management of the Gibbings Golden Cockerel books featured the work of John Buckland Wright, Blair Hughes-Stanton, Agnes Miller Parker, David Jones and Eric Ravilious. Most notably, Eric Gill was a frequent contributor to the press; not only did he produce engravings for the Golden Cockerel's most ambitious undertakings, the 1929-1931 four volume Canterbury Tales and the 1931 Four Gospels, he designed both the Golden Cockerel roman typeface in 1929 and the italic version in 1931.

These collaborations between Gill and the Gibbings, like many of the Golden Cockerel books of this era, challenge the idea of reading as solely the mental act of translating letterforms into language and of the book as merely a container for the written word. Given their size and splendour, the books were meant more for public display than solitary reading. This assumption is confirmed by their choice of source texts: the Four Gospels reproduced the text of the 1616 King James Bible and the Canterbury Tales used as its source Walter Skeat's 19th century edition. Readers interested in just reading these texts could have found much less expensive versions. The purchaser of these books was paying for their lavish illustrations, and these too raise assumptions about the intended purpose of the books. A quick survey of the illustrations in the Golden Cockerel books produced under the Gibbings reveals a high percentage of sexual images; even before he purchased the press, Gibbings first commission with it was to produce engravings for Pierre de Bourdeilles' titillating The Lives of the Gallant Ladies. This combination of erotic imagery, which is generally enjoyed privately, and the books' large size and other public display attributes, has led Robert Desmarais to suggest that they were intended for a gentleman's private library, where they could be perused and shared with his friends (Desmarais, 2007, pp. xi-xiii).

When we undertook to produce an online archive of Eric Gill's involvement with the Golden Cockerel Press we were forced immediately to confront this issue of audience. These books were not intended to be "read" in the traditional novelistic sense of following a linear narrative or argument through a book by turning pages in sequence, so standard means for displaying books using a web browser do not seem to be the best option for accessing these texts. Or, perhaps it is more accurate to say that this is but one option that we need to make available to readers, for who are we to tell readers how they can or cannot read their books? Readers, especially specialized scholarly readers, engage with books differently. Our digital interface for Gill's Golden Cockerel books will never replicate the sensation of holding one of these works in your hands and feeling the quality of the craftsmanship, but it should enable, or at least not disable, the reader reading the text, the viewer looking at the text and the scholar studying the text. By encoding our texts with maximum flexibility in mind we have been able to rapidly prototype a wide range of interfaces for engaging with the books. More importantly, by looking at how these books have been used in the past we are starting to question how they might be used in the future, and we are working to enable these alternate interfaces by making our raw data easily accessible and allowing others to contribute to the dataset by inputting their own metadata. 
Current Web interfaces for exploring images of books can be divided into two categories. The first, perhaps best know through the Google Books interface, displays each page as a single image. These interfaces also include those that present the user with a "gallery" of page images, allowing the user to move in a non-sequential fashion through the book [Figure 1]. The prevalence of these interfaces can be partially attributed to scanning technology: sheet-fed scanners can only do one page at a time, most flatbed scanners do not have a bed large enough to scan both pages at once (or the scanner operator is hesitant to press the book flat to the bed), and many users do not have access to an overhead camera scanner capable of capturing both pages at once. Screen size may also have contributed to the popularity of single page interfaces. Until relatively large widescreen monitors became readily available for the average consumer it was difficult to view an image of two adjacent pages at a resolution large enough to read, and the majority of e-book readers have screens optimized for single pages.

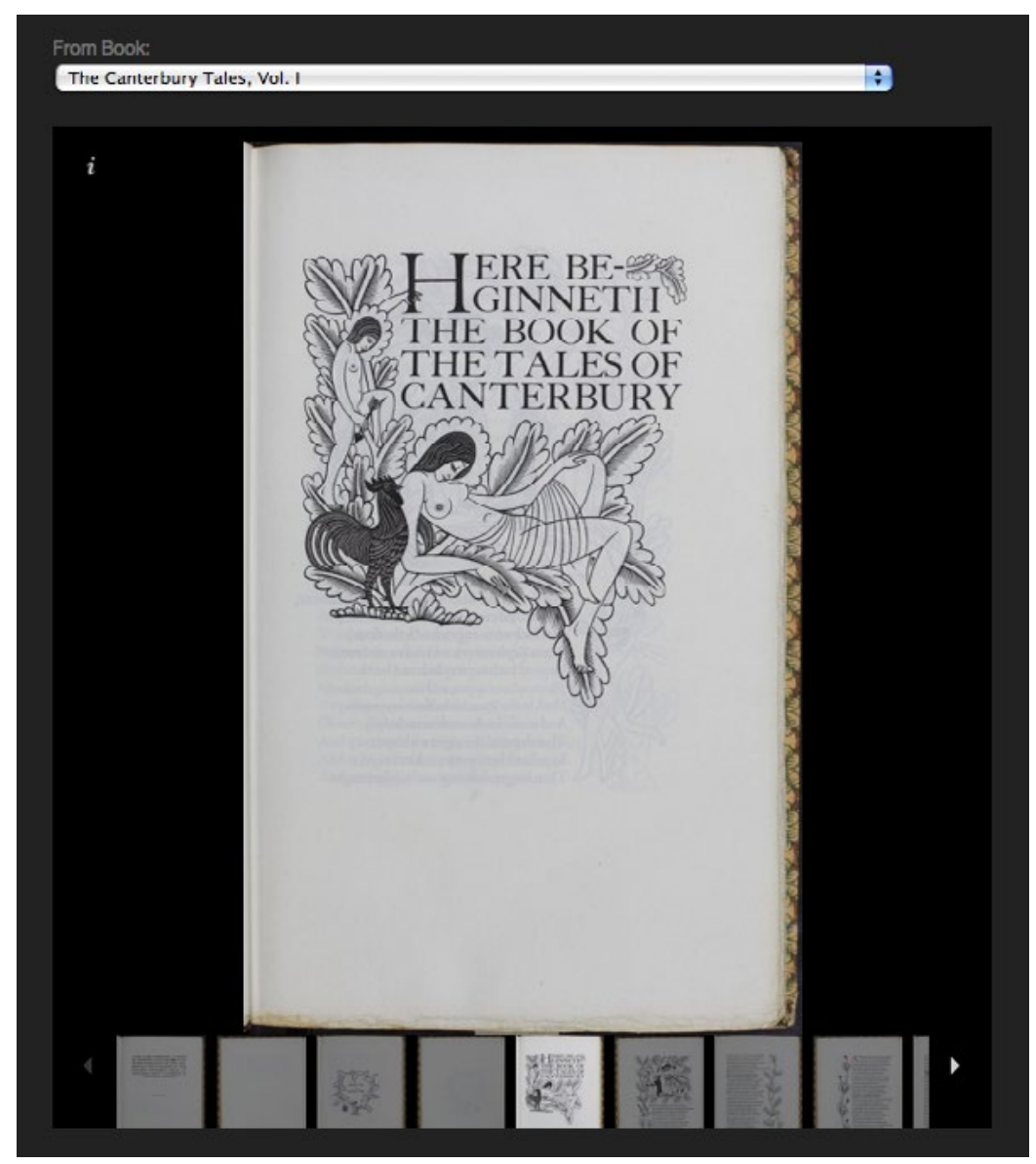

The problem is, as William Morris pointed out at the end of the 19th century, readers do not see just a single page of a book at a time - they see an opening of two adjacent pages (Morris, 1982, p. 70). The second category of web interface for viewing books is the two-up page display. The standard versions of these are near identical to the single page interfaces except that they are displaying wider images [Figure 2]. A variant of this type is the display of a quasi-book book, complete with turning pages, made popular by the British Library.
VOLUme 3 / ISSUE 4 / 2012 
Scholarly and Research

\section{Communication}

VOLUME 3 / ISSUE 4 / 2012

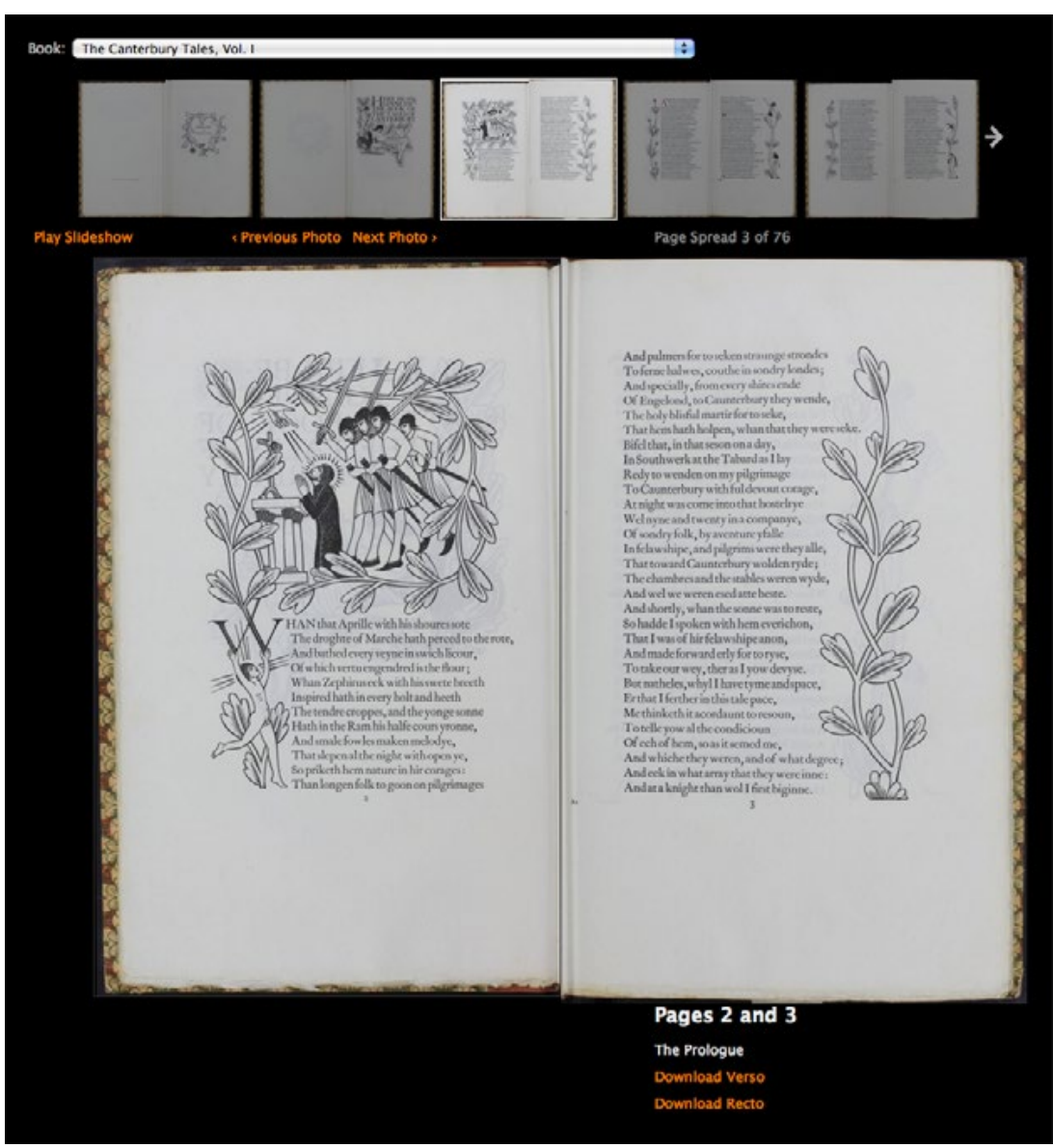

It could be argued that whether the reader sees one page or two makes little difference for the reader of an average novel, but for the reader of an illustrated work like the Golden Cockerel Canterbury Tales it is absolutely crucial. Take, for example, page 16 in the first volume [Figure 3]. The figure in the margin is obviously looking right, but his hand gesture is rather ambiguous. All ambiguity is removed when the page is viewed as part of an opening with page 17: the king on the left is calling out and the knight on the right is listening [Figure 4]. Similarly, if one only sees page 17 it is fairly clear that the knight is listening to something; the only other living creature on the page is the serpent, so one would have to assume that is to whom he is listening.

If all we were interested in is making the books available to be read, or to be looked at, one of the above interfaces, most likely the one displaying the page openings without unnecessary gimmicks, would be sufficient. But as this project is to be a scholarly resource, in addition to simply making the books available for viewing we need to make them available for study. And that means imagining the type of question a scholar might ask of the material. The blocks created from Gill's drawings were often re-used throughout the four volumes of the Canterbury Tales and in another publication, an edition of Chaucer's Troilus and Criseyde. To gain a sense of the number of illustrations that repeat and their distribution, an interface that just displays one or two images is inadequate. Rich Prospect Browsing allows you to see the whole collection simultaneously and then filter it in order to detect patterns in how the items in the collection relate to one another (Rucker, 2006, p. 2). 


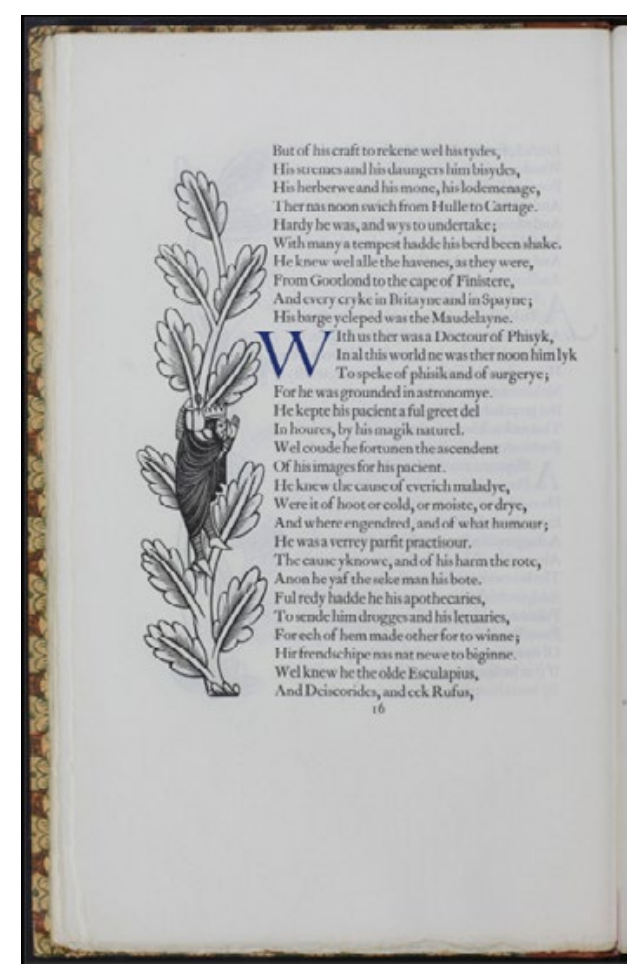

Scholarly and Research

Communication

VOLUME 3 / ISSUE 4 / 2012

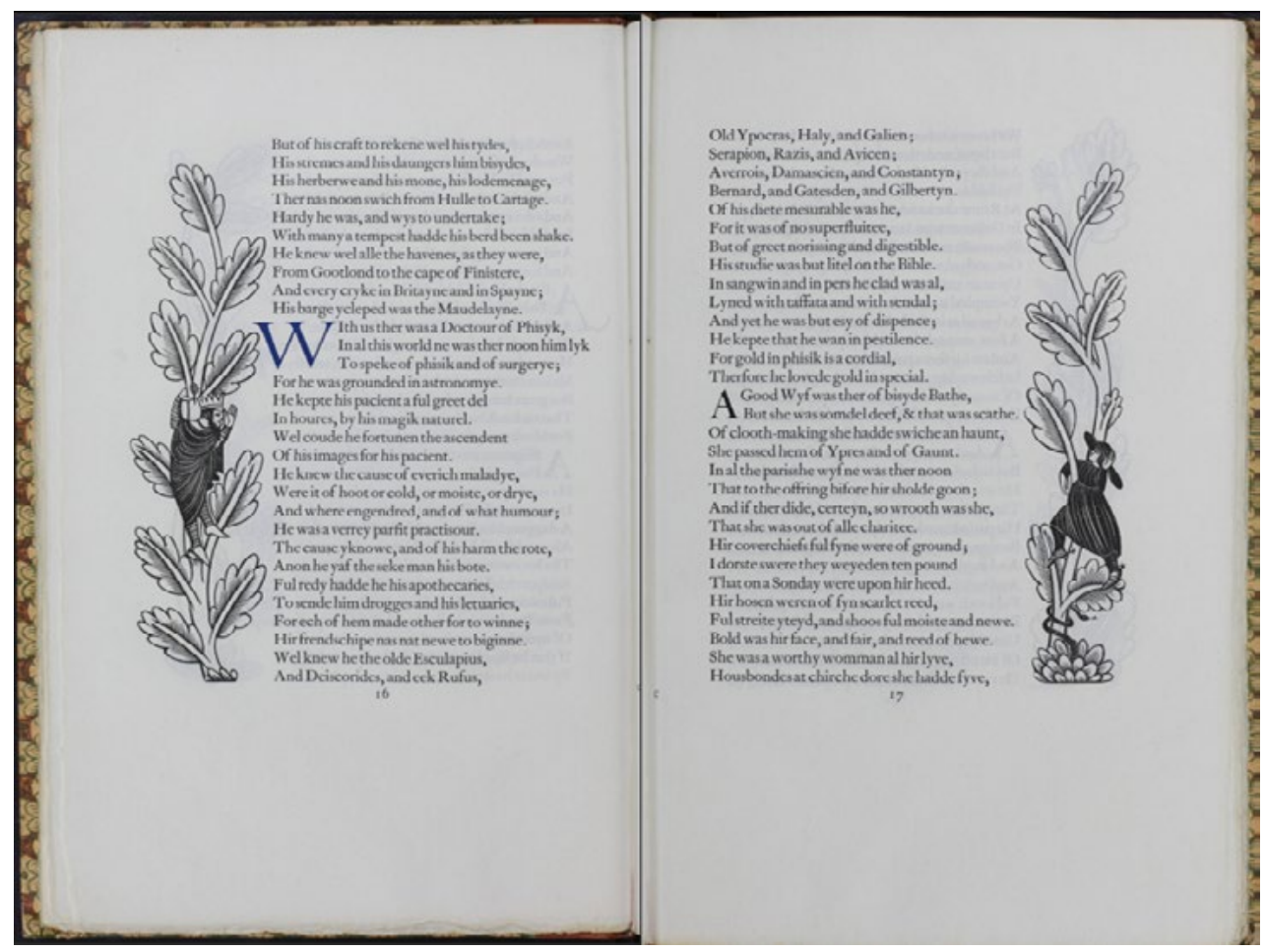

The issue of repetition also raises the question of whether the same images are always paired together. To return to the previous example: is the knight always listening to the king? We can create a network graph of the openings containing either image that reveals that in the first volume he is, but in later volumes he also listens to the martyred Archbishop of Canterbury and a hat-wearing crow. Correspondingly, the king also calls out to no one, a cherub and nude woman, and a demon [Figure 7]. To determine the possible reasons for the variance one could read the pages for any textual clues, but one quickly learns that in these books there is not always an obvious correlation 


\section{Scholarly and Research}

\section{Communication}

VOLUME 3 / ISSUE 4 / 2012 between the text and the images. Perhaps the different usages can be accounted for by examining the processes of production, so we can create a view of the sheets as they were printed and before they were bound [Figure 8].
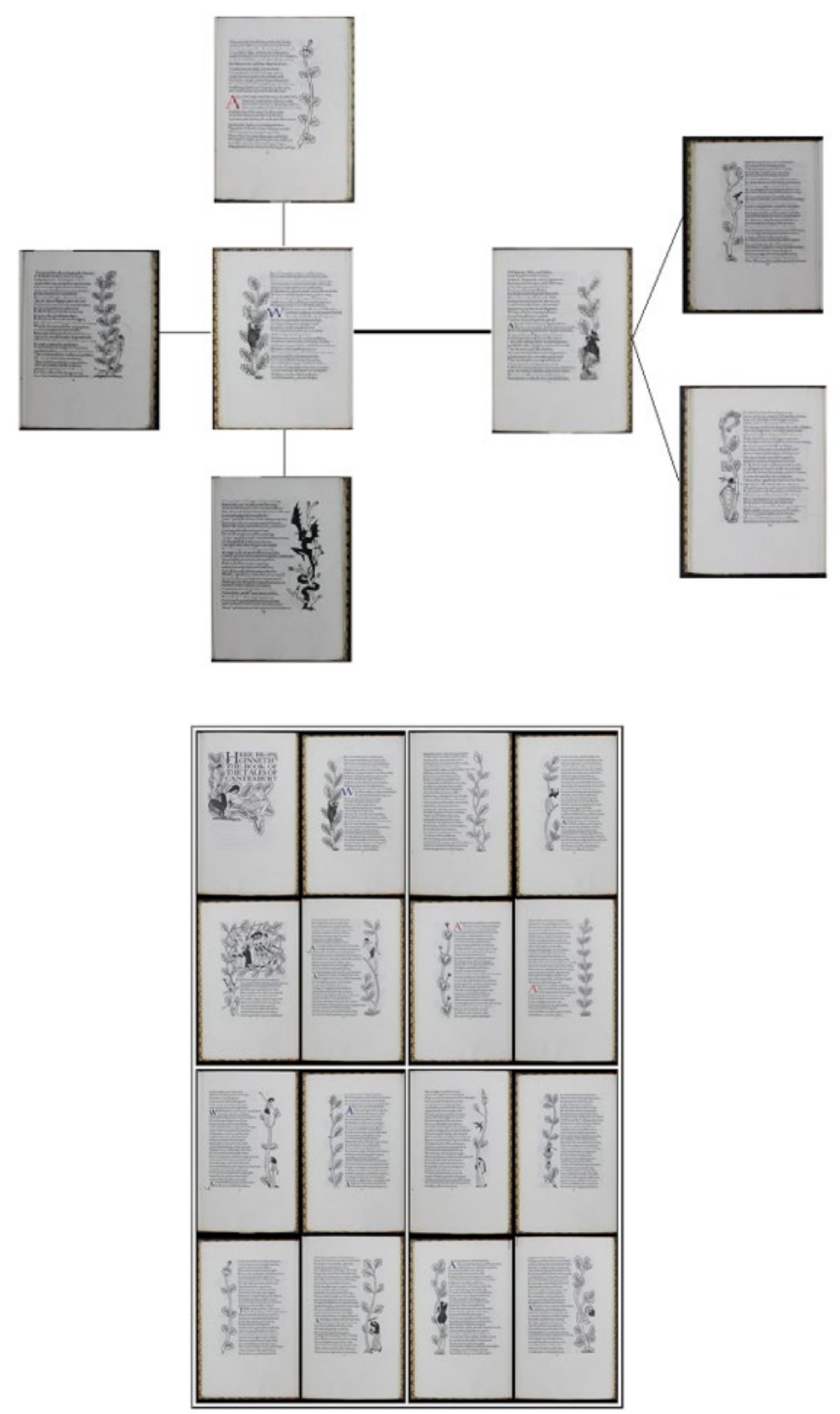

As one becomes more familiar with the books and the images they contain, questions may arise that no longer require the scholar to actually look at the pages, and instead to deal with increasingly abstract models derived from the metadata. For example, if one is interested in the prevalence of nude female figures, their posture, and their proximity to images of cherubs, one does not need to know what the individual pictures look like (or at least not initially). Even a sprawling visualization of the co-occurrence of the metadata terms used to describe the books quickly provides potentially valuable insights such as which letters appear as coloured initials or which mythical creatures embrace others [Figure 9]. 


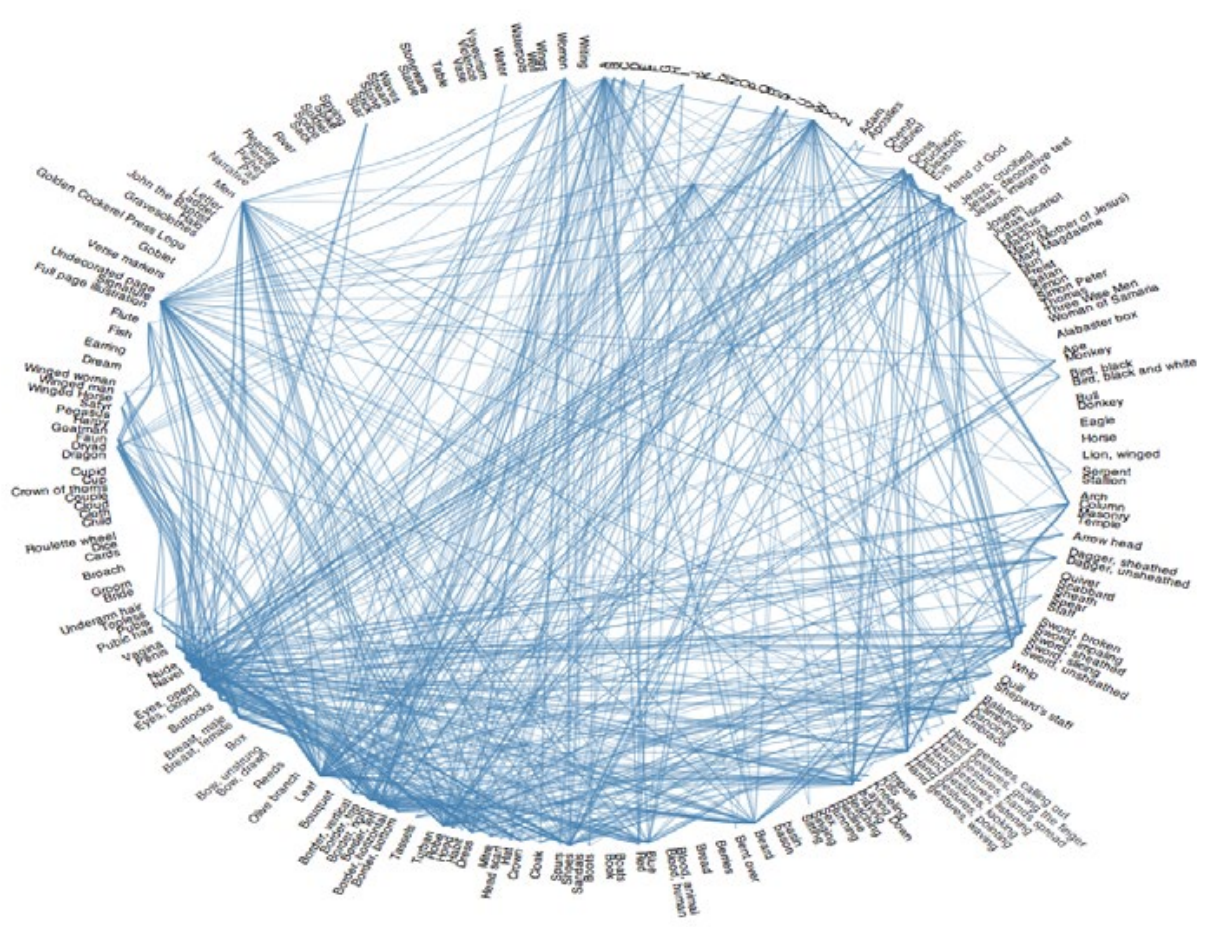

None of the preceding examples are particularly innovative on their own - all have been implemented or at least discussed by others doing similar projects. Where our project differs, however, is that we are not thinking of these means for accessing the text as "either-or;" rather, we plan to offer all of the above options and add more as we develop them. This decision has meant that the project has taken longer to launch than initially expected, but, surprisingly, not that much longer. By choosing to store our data in a flexible format that we are very comfortable working with, and by taking advantage of code written by others and shared under various open source models, we have been able to develop the above examples and experiment with others fairly rapidly.

But our "shotgun" model of offering multiple means for viewing and studying the collection also highlights several other issues with creating scholarly interfaces - for even shotguns occasionally miss their targets. Perhaps most problematically, they do little new. All of the research processes explained above could be carried out without using the computer. It might take longer (in some cases considerably longer) or require the use of a razor blade and a distracted special collections librarian, but it is possible. If, as critics such as Johanna Drucker and Lev Manovitch suggest, we need to develop research tools that go beyond replicating pre-digital processes and displaying the answers to pre-determined questions, then we need to provide interfaces to our collection not for doing things, but for enabling things to be done (Drucker, 2011, 7-8; Manovich, 2001, 115). And, quite frankly, we do not know how to do that. But hopefully someone else will, so we are working to ensure that our dataset is readily available in a variety of common formats and queryable though a variety of means.

Allowing others to access our metadata for their own purposes, however, raises a further problem: it is our metadata. When we set out to tag these images we could find no suitable authorized taxonomy. There are recognized thesauri for describing works of art but their specificity (or lack thereof) as to anatomical details and sexual acts
VOLUME 3 / ISSUE $4 / 2012$ 


\section{Scholarly and Research} Communication

VOLUME 3 / ISSUE 4 / 2012 make them less-than-ideal for Gill's work for the Golden Cockerel Press. As a result we were forced to develop our own taxonomy of terms, and our dataset is thus inherently biased toward what we imagine the scholarly uses of this material could be. As we see it there is only one-way to overcome this shortfall: by allowing users to add their own metadata (Sorenson, Harkema \& Tharani, 2011, 135). We are in the early stages of developing a framework for this, and are grappling with issues such as whether we will be allowing users to keep their tag sets distinct from other users. As a result it probably will not be available in the initial launch of the project this winter.

There is no one correct way to read a book. Different readers approach a text in different ways and for different reasons, so we as designers of interfaces for electronic reading and scholarship must strive for flexibility. This is not to say that there is not room for more strictly controlled interactions with the text; like editors of non-digital editions we also have the responsibility to use our subject expertise to provide insight into a text, which may mean producing an interface which prioritizes a certain approach to the text. But this should not be the only means to access the text. Gill's illustrations for the Golden Cockerel Press invite exploration into the social function of erotic texts, public versus private reading, fine book-making practices, and more, and we hope to provide the tools to allow scholars to engage with these texts in their multiplicity. There may also be readers who just want to read the texts and look at the pictures (for whatever reason), and we need to make sure we do not ignore their needs. Most importantly, there are, or will be, readers who want to interact with the texts in ways that we cannot imagine, and we need to do all we can to make this experimentation possible.

\section{References}

Desmarai, Robert J. (2007). Golden Cockerel's Polite Erotica. Edmonton: University of Alberta Press.

Drucker, Johanna M. (2011). Humanities Approaches to Interface Theory. Culture Machine, 12, 1-20.

Manovich, Lev. (2001). The Language of New Media. Cambridge: MIT Press.

Morris, William. (1982). The Ideal Book. William S. Peterson, Ed. Berkeley: University of California Press.

Ruecker, Stan. (2006). Experimental Interfaces Involving Visual Grouping During Browsing. Partnership: the Canadian Journal of Library and Information Practice and Research, 1(1).

Sorensen, Charlene, Harkema, Craig \& Tharani, Karim. (2011). Transcendental Metadata: A Collaborative Schema for Electronic Resource Description. Collaborative Librarianship, 3(3), 130-139. 